\title{
Teaching and Learning Social Justice through Online Service-Learning Courses
}

\author{
Kathy L. Guthrie \\ Florida State University \\ Holly McCracken \\ Capella University
}

\begin{abstract}
Creating a virtual classroom in which diverse students feel welcome to discuss and experience topics related to social justice, action, and change is a study in the value of connectedness and collaboration. Through a combination of technologies, pedagogies, and on-site experiences, virtual cultures develop that encourage the formation of demanding yet stimulating learning environments in which communications and interactions are intellectually transformative. This article explores student perceptions of their participation in an online service-learning course while working in local service organizations. Qualitative methodology was used to identify the philosophical intersection at which multiple pedagogies meet: social justice, service-learning, civic engagement, and leadership as instructed in a web-based environment. This study illustrates the capacity for intentionally constructed online educational experiences focused on social justice, civic engagement, and leadership to affect learning and to provide educators with pedagogical best practices to facilitate requisite change in teaching practice.
\end{abstract}

Keywords: Social justice; experiential education; service-learning, leadership; online learning

\section{Introduction}

Contemporary higher education has a responsibility to prepare students to solve social problems on local and global levels; to this end, teachers are challenged to enable as diverse a context for learning and living as possible (Hurtado, 2005). It is critical to educate students with respect to social issues in general and to address such issues within a context of justice and oppression (Goodman, 1995). Social justice, civic engagement, and leadership become a joint focus for collaborative discourse and action in an experientially based learning process that helps students to identify global injustices and oppression. Such opportunities assume exciting dimensions when facilitated in virtual learning environments. Directing communication and problem-based 
analyses with geographically dispersed peers who do not come into physical contact with one another defuses what Merryfield calls "triggers of difference" and thus allows a measure of anonymity, which some students find empowering and essential to discovering their individual "voices" in the unfolding of difficult dialogues (2003, p. 160). Additionally, studying with a diverse group of participants naturally creates opportunities to compare and contrast a range of experiences occurring within local cultures and communities.

Instruction in the virtual classroom, when coupled with on-site service experiences, creates opportunities for a unique combination of learning activities constructed to be individually and collectively relevant and focused on real-world problems. Freire (1970) wrote that such "Problem-posing education affirms men and women as beings in the process of becoming" (p. 84), a foundational concept that guides education in general and that has specific implications for civic engagement situated in community-based learning. The following article explores social justice pedagogy in an online service-learning course, including an analysis of student perceptions of the impact of individual and collective experiences on learning outcomes. Examining the potential of such pedagogies in a virtual environment helps educators to identify the foundational best practices and technological tools that create supportive yet challenging virtual classrooms in which relevant and meaningful interactions become vital in meeting academic goals (MacKnight, 2000).

\section{Literature Review}

Critical to the course focused on for this study is the integration of experientially based learning situated in local communities and facilitated so as to engage students from diverse backgrounds. To effectively implement social justice pedagogies instructors must do the following: 1) create virtual environments that enable ongoing communication, interaction, and relationship building; 2) develop a teaching approach that fosters autonomy and collaboration; 3) design and implement methodologies that afford opportunities for critical reflection and inquiry; and 4) deliver curricula through universally accessible technologies which support primary learning goals and the development of secondary skills (e.g., mastering Web site navigation and the use of software and hardware) (Guthrie \& McCracken, 2010a). In combination, such methods can transform teaching and learning partnerships in ways that alter learning experiences and enrich individual awareness (Cranton, 2006; Lave \& Wenger, 1991; Mandell \& Herman, 2007; Rovai, 2002).

The online service-learning course of focus for this study examines community engagement from a positive social action framework, exploring a range of leadership styles and their capacities to enact broad change. As stated in curricular objectives, upon completion of this course students are to have developed an understanding of service-learning theory through the recognition of various historical models of leadership in social change movements. This process is encouraged through reflective teaching approaches that require students to consider the relationship between the individual and society within a contemporary American context. Such approaches are particularly powerful in online classrooms, as participants explore evolving values and ethics, applying them in diverse settings to facilitate civic engagement and community-based leadership practice (Merryfield, 2003). Further, students are required to identify strategies that promote social action, 
exploring the potential for local and global change through collaboration with communities, at service sites, and among learning peers. Achieving these objectives requires that students focus on community service projects in which theories of social justice and leadership can be experienced and examined. A theoretical framework that combines experiential learning, servicelearning, and social justice guided this study; such foundational ideas both conceptually anchor this study and provide a strong framework for continuous curricular development and assessment (Einfeld \& Collins, 2008). Learning environments constructed to facilitate such a framework are discussed within the context of online teaching and learning.

\section{Constructing a Context for Social Justice through Experiential Learning}

Elias and Merriam (1980) explained: “Theory without practice leads to an empty idealism, and action without philosophical reflection leads to mindless activism” (p. 4). The role of learning situated in experience is central to social justice pedagogy; as Ayers writes, "The fundamental message of the teacher for social justice is: You can change the world” (1998, p. xvii). As such, meaningful change is rooted in experience, which is particularly powerful when combined with opportunities for critical inquiry and reflective discourse. Among the most cited of educators, Kolb introduced experiential learning theory as the process of making meaning from direct experiences, “... the process whereby knowledge is created through the transformation of experience. Knowledge results from the combination of grasping and transforming experience” (1984, p. 41). Kolb (1984) proposed two ways in which one assigns meaning to experiences: by engaging in concrete experience and subsequently by generalizing resultant learning beyond the immediate. He also proposed two ways in which one integrates experiences: through critical reflection regarding the experience and resultant learning and through active experimentation with learned concepts in new areas.

Educators have identified the importance of developing instructional environments that value experience, actively integrating it with evolving knowledge as students participate in communitybased assignments (McBrien, 2008; Taylor, 2008). Such environments foster the development and sharing of knowledge gained through both individual experience and collaborative group processes (Brookfield \& Preskill, 1999). They further allow learning to extend beyond the classroom environment, mobilizing a potential to assist broad constituencies as students apply developing concepts in local communities. (Merryfield, 2003). Such approaches incorporate a participant-centered focus, which acknowledge and utilize students' experiences, skills, and knowledge, and allow students to apply expectations and priorities to current learning opportunities and to engage one another as peers and resources.

\section{Service-Learning as a Means to Critical Inquiry}

Applied learning experiences have traditionally extended learning beyond the confines of traditional classrooms into students' communities with the goal of orchestrating both personal and broad local impact. Researchers Stanton, Giles, and Cruz (1999) and Waterman (1997) identified service learning as an experientially based instructional approach with the two-fold purpose of 
providing tangible service and meeting distinct academic goals. The connection to academic curricula and graded requirements differentiates academic service-learning, facilitated within a course structure and attached to credit generation, from co-curricular community service, completed outside the classroom, predominantly through volunteerism.

Service-learning theoretically integrates the two complex concepts of knowledge construction and community action, building on students' existing awareness of their local communities as well as the developmental learning that occurs in specific service placements (Holland \& Robinson, 2008). Pedagogical objectives are achieved through intentionally structured curricula that promote the construction of knowledge and the development of reflective practice through collaborative inquiry and that incorporate methods such as targeted readings, interactive and goaldirected discussions, team and small group activities, reflective writing, and presentations. Because it is vital for learning to be connected to service in this pedagogical framework, opportunities for critical reflection and problem-based learning are integrated into all instructional activities and assignments.

\section{Teaching for Social Justice}

Social justice pedagogy can be situated in several theoretical frameworks, including critical race theory (Tate, 1997; Yosso, 2005), identity development (Tatum, 2000), and socialization (Harro, 2000). The course in this study supports social justice education through a framework of servicelearning and leadership. Teaching for social justice adds a complex dynamic to instruction that has the potential to excite and engage students in recognizing and reacting to obstacles to full humanity (Ayers, 1998; Greene, 1998).

In this context, the complexity of an educator's role reaches far beyond personal awareness, motivation, and experience; rather, it is focused on facilitating relationships. Connections with students in particular moments become the focus of the teaching and learning partnership. While learning requires choice and action from students, teaching requires relationship: the invitation to embark on journeys of personal development within an exploration of new information and theoretical frameworks. Social justice education becomes more than teaching about injustices; inherent in this pedagogy is a commitment to providing students with tools to work towards the goal of action on both local and global levels (Kincheloe, 2004).

Educators for social justice must create learning environments that include numerous entry points for learning and multiple pathways for practice and ongoing investigation (Ayers, 1998). The instructional environment must be at once supportive and challenging (Sanford, 1967). Situated in the framework of service-learning and leadership, this course strives not only to educate students about social justice issues, but also to empower them to lead others in creating action and change. 


\section{Using Technologies to Extend Instructional Impact}

A philosophical approach combining progressive attributes (focusing on the formation of active teaching and learning partnerships facilitated via collaborative problem solving), humanist attributes (promoting actualization through autonomy and self-directedness), and radical attributes (facilitating social change through individual and collective action) directed the selection of both instructional methods and technologies to shape teaching and learning processes, promote individual awareness and exploration, and guide locally based social action (Kanuka, 2008). Learning technologies assume a unique primacy when linking on-site learning experiences and virtual coursework with the overall goal of enabling students to engage with their local communities and to participate in relevant dialogue with geographically dispersed peers. When used in conjunction with instructional methods that promote reflection, inquiry, and collaboration, technologies enable participants to shift dialogue beyond one-dimensional information sharing to significant learning originating in experiential settings (Barab, Thomas, \& Merrill, 2001). Meyers (2008) suggests that discussions structured to facilitate critical discourse and inquiry are particularly effective when carried on in virtual environments insofar as they encourage explorations of issues related to social equity; the results of this study reinforce his theory insofar as dialogue was successfully extended beyond classroom confines to distinctive communities throughout the United States and into Mexico and England.

Garrison, Anderson, and Archer (2000) found that virtual classrooms indeed provide environments in which reflective discourse is fostered and critical inquiry nurtured as a means to extend positive, collaborative educational transactions. Their community of inquiry model (2000) not only establishes a framework for realizing the potential of reflective, experientially based pedagogies in virtual learning environments, but also identifies important components essential to high-quality, accessible learning. A commitment to what the researchers (2000) refer to as teaching, social, and cognitive presence provides the foundation upon which to develop and instruct web-based curricula and in combination guided the design and implementation of the course at the center of this study. By uniting these key aspects of the instructional process, teachers formed meaningful partnerships with students that facilitated ongoing dialogue, fostered developing insight, and identified and documented individual and collective learning outcomes.

Educational technologies were selected based on their capacities to facilitate interaction, communication, and collaboration in order to generate shared learning goals and to solve common problems. Geographical differences were exploited or minimized as relevant to curricular outcomes through the strategic use of both synchronous and asynchronous activities and events. It was a priority to ensure continuous interactions between all stakeholders engaged in the service triad (which included students, teachers, and personnel in community-based organizations); this enabled a concerted focus on both curricular objectives and placements' priorities. To meet instructional goals, ongoing communications were facilitated within the structure of a learning management system in conjunction with the integration of asynchronous discussion boards, blogs, and email as well as synchronous chat, telephone usage, and virtual conferencing platforms that enable text, audio, and video interactions. Additionally, students were encouraged to utilize social networking and free video-sharing platforms to the extent that they 
augmented their experiences in relevant ways. Finally, information management functions were enabled to distribute and archive course content, using document and file sharing, text-based lectures, podcasts, and e-books. While the technologies utilized in the instruction of this course are commonly used in educational settings, the combination of such telecommunications with experientially based learning uniquely compounded individual and collective learning outcomes as well as community impacts.

\section{Methodology}

The purpose of this study was to explore student learning that resulted from participation in a web-based service-learning course at a small Midwestern four-year institution in the United States. The exploratory nature of this study determined the qualitative design approach.

\section{Research Design}

Information about such student learning was constructed qualitatively through a survey and an interview. This approach draws upon the writing of qualitative scholars who present a constructivist approach (see, for example, Charmaz, 2000; Denzin \& Lincoln, 2005; Guba \& Lincoln, 2005) and tends to be less open and interpretive than the traditional constructivist assumptions. A constructivist approach assumes a relative ontology, a subjective epistemology, and a naturalistic set of methodological procedures (Guba \& Lincoln, 2001). A relative ontology indicates that there are multiple realities; a subjective epistemology assumes that the respondent and knower co-create meaning, and a naturalistic set of methodological procedures investigates the natural world (Creswell, 1994). While findings using this constructivist paradigm are typically presented in terms of grounded theory or pattern theories (Guba \& Lincoln, 2005), this approach examines the phenomenon of learning from a combination of online coursework coupled with onsite community service as presented through both written narratives and oral interviews. The field of qualitative research is constantly challenging the distinction between what is real and what is constructed. This comes through an understanding that all events are made real through interaction, discourse, conversation, and narratives (Denzin \& Lincoln, 2005). This study attempted to understand the phenomenon of learning through qualitative survey and interview.

Demographic information related to participants as well as their initial reactions were obtained through the survey process; students were then invited to provide their contact information in order to participate in the interview component. The main task in the interview segment of the study was to develop an awareness of students' statements and their associated or underlying meaning (Kvale, 1996). Collecting information through combined survey and interview methods allowed students to identify and reflect upon insights related to the impact of their experiences inasmuch as they shared their perceptions of their lived world (Kvale, 1996). This led to the articulation of specific knowledge about personal learning, which, in turn, enhanced their awareness of meaning and relevance as well as their understanding of social justice pedagogy facilitated in a web-based classroom. 
Description, analysis, and interpretation are three ways of organizing and reporting qualitative data (Wolcott, 1994), and these approaches to organizing and reporting data were used. After the 28 surveys were collected and the 15 interviews conducted, data was analyzed to identify both common themes and unique areas of learning. An explanation of the data collected after each of the interviews was constructed by describing additional elements, such as non-verbal communication identified through the process; such impressions were recorded immediately following the interviews and transcribed following their conclusion. Transcripts from the interviews were assessed and reviewed; data that aligned with potential codes were highlighted. Phrases and words were used to determine refined codes for each participant. Emerging themes were also identified when the same ideas surfaced in three or more student transcriptions. Once emerging themes were studied, relationships among those themes were examined. Two researchers analyzed this data separately, and only themes both researchers found were discussed. One researcher taught this course and the second researcher had no prior knowledge or experience with the course and looked strictly at the responses from the students participating in this study.

\section{Participant Selection and Recruitment}

Potential participants were contacted by gaining access through the academic department at the small public Midwestern four-year institution where the study was conducted. Enrollment lists from the past three semesters in which a specific online service-learning course focused on social change and leadership were accessed. At the time of request, 57 students had completed the course and 42 students were still enrolled in courses at the university. Once a list of possible participants was verified each individual was contacted via email with a link to the online survey. Of the 42 students contacted, 28 completed the survey, for a $67 \%$ response rate. Of these 42 participants 17 consented to be interviewed and 15 students were actually interviewed or $36 \%$ of the total potential participant pool.

\section{Course Description}

At the time of this study, the specific course used had been taught in an online format for five semesters. This course examines community engagement from a positive social change framework and explores how different leadership styles enact positive change. Topics related to social justice are specifically discussed throughout the course. Requirements include the completion of individual action plans, 60 hours of community service, reflection journals, participation in structured discussions, and reflective essays that conclude with final culminating papers. Students are asked to select non-profit agencies and organizations in which their service will be performed. Once service sites are selected and confirmed with agency representatives, students are asked to determine individual learning goals for successful completion of the community service experiences. A solid learning environment is created by providing an opportunity for students to apply learning in the classroom to an experience and by providing guidance in making meaning from a specific experience. 


\section{Results}

Of the 28 students participating in the study, 17 were between 20 and 24 years of age, five were between 25 and 29 years of age, three were between 30 and 40 years of age and three were between the ages of 41 and 55. Twenty-one students self-identified as Caucasian and seven selfidentified as minorities; four were African-American, one was multiracial and two were Latino/a. The majority of students responding were female, with only 10 respondents male. Only one student lived outside of the United States at the time of the study. Twenty students identified themselves as full-time and seven students stated they only took classes online, which mirrored the institution's overall student demographics. Students participating in this study represented a wide range of disciplines. Business, including management and accounting majors, was the most represented, with nine students; five students were in criminal justice and legal studies, four students were studying computer science, four students were in communications, three in political science, two in psychology, and one in chemistry.

The data indicated that students studying social justice though a combined approach using online classrooms and on-site experiences did indeed report a positive impact on their learning. Specifically, three main themes emerged as having the most impact: learning new concepts or theories about social justice, engaging in critical discourse with peers related to social justice, and participating in opportunities for structured reflection about course materials and activities as well as on-site experiences.

\section{Learning New Concepts of Social Justice}

In order to better understand student perceptions about the impact of the service-learning course, participants were asked to discuss their learning; this question was asked on both the survey and in the interview. Students participating in this study responded that they learned a new concept or theory in the areas of social justice, leadership, and/or civic engagement as a result of their participation. Specifically, six students learned something new in relation to social justice, five students reported having learned both new social justice and leadership concepts, four students noted that they learned new social justice and civic engagement concepts, and two students said they learned something new in all three areas of social justice, leadership, and civic engagement.

During the interview, one student stated that learning about the concepts inherent in social justice, leadership, and civic education made him more aware of them in his everyday life. He said,

I never really thought about leadership, social justice and volunteerism as being interconnected. This class not only told us how they were connected, but we could then see it in our service sites. Once I knew how to think about these topics, I could look for them. Service, social justice and leadership is [sic] everywhere and is [sic] seen every day. I would say that is the biggest thing I learned from this class. 
Another student reported, “This course not only taught me concepts around service, leadership and social justice, but it gave me the opportunity to observe and even practice some of these concepts through my service.” This student explained how the course gave her the opportunity to experience the concepts she learned, providing a living laboratory in which to experience issues related to social justice and civic engagement.

Several students reported that they learned about the general concepts of social justice as actualized through placement experiences. One student said, "I had heard the term social justice, but really didn't know what it meant. Now that I know, I am actually embarrassed that I did not really understand what it was about." Another student emphasized, "The whole idea of social justice is what I learned. I live in a town where we are all the same. This class taught me that social justice is much more than a racial thing, much, much more than that." Another student commented that specific concepts of social justice were especially valuable, noting, "The cycle of oppression that we learned when we were studying social justice made complete sense. I never thought about social equality in that way before.” Insight about students' perceived impact of their participation in the online service-learning course contributed to possible best practices for educators interested in utilizing social justice pedagogy.

\section{Fostering Critical Discourse Related to Social Action and Change}

To facilitate discussion about social justice, questions were posed on an asynchronous discussion forum inviting students both individually and collectively to consider assigned readings in view of the ways social justice issues were evidenced in their community service experiences. During the interviews, students were asked, "What are your reactions to discussing issues of social justice in this online course?” Of the 15 interviewed, all students stated that they learned from directed discussions with their peers. One student specifically said, "I did not even know what social justice was before this class. I really liked that we could talk about these issues and then experience them in our service. . It totally makes sense to have a class like this.”

Ten students said they had never talked about such topics in an online class before. During the interviews, one student responded, "These were like no other discussions I have had in an online class. It made me think about how social justice issues play a role in not only my community service, but my daily life." Another student noted, "When we first started talking about social justice issues a few of us were saying how we had never talked about such topics online before. It was a breath of fresh air." Yet another student said, "I have never talked about social justice before, let alone in an online class before.”

When asked to describe their reactions to discussing these concepts via web-based discussion, seven students responded that they looked forward to conversations about social justice. One student said, "I loved the conversations we had in this class, especially when we were talking about social justice. The fact that students were all over the world doing service made these conversations especially interesting." Another student said, "I looked forward to hearing other people's experiences. Talking about a time we have been discriminated against and when we discriminated against someone was eye opening.” 
Merryfield (2003) determined that online discussion "acts as a veil to protect people as they reveal, question, and take risks” (p. 154), explaining that when people have only text to respond to, they are attracted to people and respond to them based on what they have written: as evidenced through students' self-reports, such experience can be profoundly different from oral discussions conducted in physical classrooms. Building community is especially important when facilitating conversations that hold the potential to be intensely personal and revealing. One student said, "When I first saw the possible controversial topics, I thought people would be disrespectful, but actually I learned more through these conversations and looked forward to them.” Student perceptions of their online conversations about social justice provide a meaningful understanding of the impact this pedagogy had on learning.

\section{Facilitating Engagement through Structured Reflection}

The practice of critical and engaged reflection has a dramatic impact in facilitating learning around social justice, and the process is made particularly visible and interactive through the use of threaded discussions (Merryfield, 2006). Interview participants were asked, "In this course, what role did reflection play in your personal learning?” Of the 15 students interviewed, 13 students responded that reflection had a positive impact on their personal learning. One student stressed, "Reflection played a huge part in my learning. This course brought up things that I have never thought about. It made me look at the community service I was doing in a different light." Another student emphasized that reflection was especially important to discussing social justice issues: "Just as our instructor told us, reflection is about making meaning. After our discussions, especially around social justice and the cycle of oppression, I could reflect in my journals which helped me get my thoughts straight." A second student stated, "The reflection journals and reflective essays in this course gave me an opportunity or should I say forced me to think through the tough issues we were talking about, like inequality and social justice.”

\section{Discussion and Implications}

Teaching focused on social justice and action anchored in service-learning and leadership theory hold a range of implications for post-secondary education, particularly in blended learning environments that effectively combine web-based instruction with on-site placement experiences in diverse communities. The results of this study indicate that it is possible to reach broad participant groups by raising awareness of commonalities as well as differences and by facilitating cognitive and affective connections to local and global issues, people, and contexts through the use of a variety of media-based applications. When combined with pedagogies that foster the development of critical dialogue, personal insight, and active engagement, such technologies can extend learning beyond regional confines and identities to enable individual growth and to increase capacities for understanding and awareness. Moreover, the rich dialogue generated through such courses has the potential for impact far beyond a single classroom and student as ideas and insights gleaned in online classrooms extend to a range of communities with anomalous strengths and needs. 
Students participating in this study repeatedly remarked that opportunities for individual and collective reflection allowed them to develop a deeply personalized awareness of issues related to social justice, action, and change as they explored new ideas and applied them to past and present experiences with a focus on the continued generation of future ideals and goals. A combination of readings that promote cognitive growth, activities that encourage reflection and critical inquiry, and discussion-based analyses of real-time experiences occurring in on-site placements enabled a gradual and expanded consciousness that participants emphasized was not typically a component of their undergraduate learning. Hunt (1998) identified the importance of teaching for social justice as "a reminder. . of the powerful stories which inspire us to work toward change, to make the world a better place” (p. xiii). Illustrating learning through such stories fostered insight into the complexity of social responsibility, and reflective discussions were often the means by which students constructed the meaning of such stories and experiences. While online technologies enable extended discussions, guiding students on such reflective journeys presents challenges for both teachers and participants. For example, when students are not able to fully utilize selected technologies, valuable instructional time may be lost in providing requisite technical training. Also, when interactions are not instantaneous, as a result of asynchronous participation, those allimportant "aha” moments may be significantly delayed and critical teaching opportunities missed. It is therefore essential that teachers establish detailed criteria and schedules for responses and maintain frequent interaction with students as they reveal observations, insights, and critical analyses.

Individual experiences and backgrounds, learning styles, and academic competencies affect the conceptual development possible in a course that holds at its center very personal and often revealing interpretation. The use of educational technologies enables educators to reach a wide range of students who participate from multiple time zones, according to widely varying schedules, under sometimes challenging conditions, and in unique organizational and community settings. This level of diversity impacts not only the selection of technologies (for example, taking into account the ways individuals and organization access and navigate the Internet), but also course content and available resources that continue to be shaped throughout the academic term. Students themselves introduce a multitude of resources in the form of social networks, Web sites, news articles, and videos, each of which has the potential to effect curricular changes that affect learning outcomes. Such changes can enrich engagement, providing unique and timely alternatives that facilitate both individual and collective analyses. It is incumbent upon instructors to recognize and seize such opportunities to capitalize on the rich diversity in online classrooms to the extent that such changes enhance inclusion. Explorations of broader issues, such as socioeconomic advantage and privilege and their relationship to accessing information technology and developing skills in information literacy and the role culture plays in interaction and communication, continue to be critical to ensuring that curricular goals and instructional methods are congruent with the larger academic field, pedagogical priorities, student experiences, and social realities (Guthrie \& McCracken, 2010b).

Understanding issues related to social justice, action, and responsibility involves complex thinking about highly personal experiences. During this process, areas of new learning are integrated with thinking that continues to develop over time. To illustrate their evolving 
awareness, participants share intimate details about their lives, successes, failures, and relationships; this process encourages an intensely personal instructional experience. Students often have not been exposed to a wide variety of social justice issues nor have they cultivated the cognitive or relational abilities necessary to identify and interpret key experiences that become essential to their learning. This meaning-making process requires that participants possess a high degree of self-directedness, autonomy, and motivation in order to optimally integrate learning experiences. The development of such skills, when coupled with learning new technologies, presents multiple challenges for management within a relatively short period of time (in the instance of this study, a sixteen-week semester). When teaching courses that require the development of such an expansive array of abilities, instructors must balance a wide variety of roles and responsibilities, many of which evolve based on the composition of both the classroom and the organizations in which students serve.

The results of this study reinforce previous research indicating that the combination of active discussions and intentionally structured assignments supports individualized reflection and collaborative learning when utilized within technology-rich learning environments (Palloff \& Pratt, 2007; Tseng, Wang, Ku, \& Sun, 2009). Students reported a strong sense of learning from open discussion and the mediation of difficult dialogues that ultimately reinforce complex understanding. While reflective and collaborative inquiry enhances connectedness and community building, supporting students with a wide range of competencies as they develop the skills necessary to generate and sustain such engagement on an ongoing basis requires close attention and continuous and active coaching. Sujo de Montes, Oran, and Willis (2002), as well as Kanuka (2008), remind us that computers are not culturally neutral but amplify the characteristics of those who design, promote, and use them. Sujo de Montes, Oran and Willis (2002) note, "Because the amplified characteristics are those of the dominant culture, students at the margins [continue to be] disadvantaged. As [online] classrooms become more culturally diverse. ... it is not safe to ignore issues of race, ethnicity and power, or assume they are in the 'off' mode" because participants are not physically visible (p. 268). Teachers instructing curricula that involve multiple levels of learning are challenged to maintain their focus on the social realities demonstrated in their online classrooms and on the ways in which they impact the integration of overall learning and the application of technologies.

\section{Conclusion}

To participate in students' individual development as they actualize and integrate personalized meaning related to social justice and civic engagement in local communities is genuinely exciting. As study results indicate, helping participants to develop individual voices is, in fact, thrilling as they demonstrate evolving leadership skills that may result in positive social action in their local communities. Without the aid of technologies, such rich dialogue and experience would be limited to a regional analysis; through the use of media-based instruction, educational experiences extend a global reach, providing compounded meaning and impact (Merryfield, 2001). It is the intent of this article to contribute to the growing and substantial literature that addresses the potential for a global impact of intentionally constructed educational experiences focused on social justice education through the use of technology. Merryfield (2006) cautions, 
"We can use electronic technologies to counter mainstream academic knowledge, overcome teachers' parochialism and national chauvinism, and challenge White middle-class American assumptions about power, inequity, and privilege. Or, we can use these new technologies to justify the status quo” (p. 297). As she so aptly remarks, “The choice is ours” (2006, p. 297). 


\section{References}

Ayers, W. (1998). Popular education: Teaching for social justice. In W. Ayers, J. A. Hunt, \& T. Quinn (Eds.), Teaching for social justice (pp. xvii-xxv). New York: New Press.

Barab, S., Thomas, M. \& Merrill. (2001). Online learning: From information dissemination to fostering collaboration. Journal of Interactive Learning Research, 12(1), 105-143.

Brookfield, S. D., \& Preskill, S. (1999). Discussion as a way of teaching. San Francisco: JosseyBass.

Charmaz, K. (2000). Grounded theory: Objectivist and constructivist methods. In N. K. Denzin \& Y. S. Lincoln (Eds.), Handbook of qualitative research (2nd ed., pp. 509536). Thousand Oaks, CA: Sage.

Cranton, P. (2006). Understanding and promoting transformative learning. San Francisco: Jossey-Bass.

Creswell, J. (1994). Research design: Qualitative and quantitative approaches (2nd ed.). Thousand Oaks, CA: Sage.

Denzin, N. K., \& Lincoln, Y. S. (2005). The SAGE handbook of qualitative research. Thousand Oaks, CA: Sage.

Einfeld, A., \& Collins, D. (2008). The relationships between service-learning, social justice, multicultural competence, and civic engagement. Journal of College Student Development, 49(2), 95-109.

Elias, J. L., \& Merriam, S. (1980). Philosophical foundations of adult education. Malabar, FL: Robert E. Krieger.

Freire, P. (1970). The pedagogy of the oppressed. New York: Continuum.

Garrison, D. R., Anderson, T., \& Archer, W. (2000). Critical inquiry in a text-based environment: Computer conferencing in higher education. The Internet and Higher Education, 2(2-3), 87-105.

Goodman, D. (1995). Difficult dialogues: Enhancing discussions about diversity. College Teaching, 43(2), 47-52.

Greene, M. (1998). Teaching for social justice. In W. Ayers, J. A. Hunt, \&

T. Quinn (Eds.), Teaching for social justice (pp. xxvii-xlvi). New York: New Press. 
Guba, E. G., \& Lincoln, Y. S. (2001). Competing paradigms in qualitative research. In C. F. Conrad, J. G. Haworth, \& L. R. Latucca (Eds.), Qualitative research in higher education: ASHE reader series (2nd ed., pp. 57-72). Boston:

Pearson Custom Publishing.

Guba, E. G., \& Lincoln, Y. S. (2005). Paradigmatic controversies, contradictions, and emerging influences. In N. K. Denzin \& Y. S. Lincoln (Eds.), The SAGE handbook of qualitative research (3rd ed., pp. 191-215). Thousand Oaks, CA: Sage.

Guthrie, K. L., \& McCracken, H. (2010a). Promoting reflective discourse through connectivity: Conversations around service-learning experiences. In L. Shedletsk \& J. E. Aitken (Eds.), Cases on online discussion and interaction: Experiences and outcomes. Hershey, PA: IGI Global.

Guthrie, K. L., \& McCracken, H. (2010b). Making a difference online: Facilitating service-learning through distance education. The Internet and Higher Education, 13, 153-157.

Harro, B. (2000). The cycle of socialization. In M. Adams, W. J. Blumenfeld, R. Castaneda, H. W. Hackman, M. L. Peters, \& X. Zuniga (Eds.), Readings for diversity and social Justice (pp. 15-21). New York: Routledge.

Holland, B., \& Robinson, G. (2008, Summer). Community based learning with adults: Bridging efforts in multiple sectors [Electronic version]. New Directions in Adult and Continuing Education, 118, 17-30.

Hunt, J. A. (1998). Of stories, seed and the promises of social justice. In W. Ayers, J. A. Hunt \& T. Quinn (Eds.), Teaching for social justice (pp. xiii-xv). New York: New Press.

Hurtado, S. (2005). The next generation of diversity and intergroup relations research. Journal of Social Issues, 61(3), 595-610.

Kanuka, H. (2008). Understanding e-learning technologies-in-practice through philosophies-inpractice. In T. Anderson (Ed.), The theory and practice of online learning (pp. 91-118). Retrieved from http://www.aupress.ca/books/120146/ebook/99Z_Anderson_2008Theory and Practice of Online Learning.pdf.

Kincheloe, J. L. (2004). Critical pedagogy primer. New York: Peter Lang.

Kolb, D. (1984). Experiential learning: Experience as the source of learning and development. Upper Saddle River, NJ: Prentice Hall.

Kvale, S. (1996). InterViews: An introduction to qualitative research interviewing. 
Thousand Oaks, CA: Sage.

Lave, J., \& Wenger, E. (1991). Situated learning: Legitimate peripheral participation. Cambridge, UK: Cambridge University Press.

MacKnight, C. B. (2000). Teaching critical thinking through online discussions. Educause Quarterly, 4, 38-41.

McBrien, J. L. (2008). The world at America's doorstep: Service learning in preparation to teach global students. Journal of Transformative Education, 6. Retrieved from http://jtd.sagepub.com/cgi/content/abstract/6/4/270.

Mandell, A., \& Herman, L. (2007). The study and transformation of experience. Journal of Transformative Education, 5 (4), 339-353. Retrieved from http://jtd.sagepub.com/content/5/4/339.abstract.

Merryfield, M. M. (2001). The paradoxes of teaching a multicultural education course online. Journal of Teacher Education, 52(4), 283-299.

Merryfield, M. M. (2003). Like a veil: Cross-cultural experiential learning online. Contemporary Issues in Technology and Teacher Education, 3(2), 146-171.

Merryfield, M. M. (2006). WebCT, PDS, and democratic spaces in teacher education. International Journal of Social Education, 21(1), 73-94.

Meyers, S. (2008). Using transformative pedagogy when teaching online. College Teaching, 56(4), 219-224.

Palloff, R. M., \& Pratt, K. (2007). Building online learning communities: Effective strategies for the virtual classroom. San Francisco: Jossey-Bass.

Rovai, A. (2002). Building sense of community at a distance. International Review of Research in Open and Distance Learning, 3(1). Retrieved from http://www.irrodl.org/index.php/irrodl/article/viewArticle/79/152

Sanford, N. (1967). Where colleges fail: A study of the student as a person. San Francisco: Jossey-Bass.

Stanton, T. K., Giles, D. E., \& Cruz, N. I. (1999). Service-learning: A movement's pioneers reflect on its origins, practice, and future. San Francisco: Jossey-Bass.

Strait, J., \& Sauer, T. (2004). Constructing experiential learning for online courses: The birth of e-Service. EDUCAUSE Quarterly, 27(1). Retrieved from 
http://www.educause.edu/EDUCAUSE+Quarterly/EDUCAUSEQuarterlyMagazineVolu $\underline{\mathrm{m} / \text { ConstructingExperientialLearni/157274 }}$

Sujo de Montes, L. E., Oran, S. M., \& Willis, E. M. (2002). Power, language, and identity: Voices from an online course. Computers and Composition, 19, 251-271.

Tate, W. F. (1997). Critical race theory and education: History, theory, and implications. Review of Research in Education, 22(1), 195-247.

Tatum, B. D. (2000). The complexity of identity: Who am I? In M. Adams, W. J. Blumenfeld, R. Castaneda, H. W. Hackman, M. L. Peters, \& X. Zuniga (Eds.), Readings for diversity and social justice (pp. 9-15). New York: Routledge.

Taylor, E. (2008). Transformative learning theory. New Directions for Adult and Continuing Education, 119, 5-15.

Tseng, H., Wang, C., Ku, H., \& Sun, L. (2009). Key factors in online collaboration and their relationship to teamwork satisfaction. Quarterly Review of Distance Education, 10(2), 195-206.

Waterman, A. S. (1997). Service-learning: Applications from the research. Mahwah, NJ: Lawrence Erlbaum Associates.

Wolcott, H. F. (1994). Transforming qualitative data: Description, analysis and interpretation. Thousand Oaks, CA: Sage.

Yosso, T. J. (2005). Whose culture has capital? A critical race theory discussion of community cultural wealth. Race Ethnicity and Education, 8(1), 69-91.

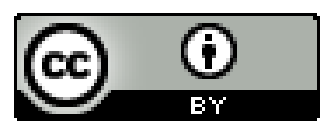

